\title{
Neuropathic pain and functional reorganization in the primary sensorimotor cortex after spinal cord injury
}

\author{
Authors: C. R. Jutzeler $P h D^{1}$, P. Freund MD PhD ${ }^{1,3,4}$, E. Huber MSc ${ }^{1}$, A. Curt MD ${ }^{1}$, and
} J.L.K. Kramer $P h D^{1,2}$

1. Spinal Cord Injury Center, University Hospital Balgrist, University of Zurich, Zurich, Switzerland

2. School of Kinesiology, ICORD, University of British Columbia, Vancouver, BC, Canada

3. Department of Brain Repair and Rehabilitation, UCL Institute of Neurology, University College London, London, UK

4. Wellcome Trust Centre for Neuroimaging, UCL Institute of Neurology, University College London, London, UK

Disclose of funding: The study was supported by the Swiss National Science Foundation (SNF) and the Clinical Research Priority Program "Neurorehab" of the University of Zurich, Switzerland. John Kramer was supported by postdoctoral funding from the International Foundation for Paraplegia - Zurich, a Michael Smith Foundation for Health Research and Rick Hansen Scholar Award, and a North American Spine Society Clinical Travel Fellowship.

Corresponding author:

Catherine R. Jutzeler

Spinal Cord Injury Center University Hospital Balgrist Forchstrasse 340 8008 Zurich, Switzerland cjutzeler@paralab.balgrist.ch Phone: +41443863741

Fax: +41 443863731

URL: www.sci-research.uzh.ch 


\begin{abstract}
Refractory to most types of treatment, neuropathic pain (NP) is a major problem for people living with spinal cord injury $(\mathrm{SCl})$. Among problems related to treatment, underlying mechanisms are poorly understood. The aim of the present study was to investigate the association between cortical reorganization and NP after SCI. 24 individuals with sensorimotor complete and incomplete para- and tetraplegia (12 suffering from NP, 13 pain-free) and 31 healthy subjects were examined. Functional magnetic resonance imaging was used to assess activation in primary somatosensory and motor cortices in response to motor (i.e., active and passive wrist extension) and sensory (i.e., heat and brushing) tasks applied on the dorsum of the hand. In individuals with $\mathrm{SCl}$, there were no group-level differences in task related activation (i.e., movement or sensory) compared to healthy control subjects. However, based on the Euclidean Distance measure, individuals with SCI demonstrated a lateral shift of peak activity in primary sensory and motor cortices $(p<0.05)$. Among those with NP, chronic pain intensity inversely correlated with magnitude of the shift in the primary motor cortex during active wrist extension. The findings reveal that neuropathic pain in motor and sensory tasks at/above the level of lesion is not associated with increased plasticity. In line with previous studies changes in somatotopy and activation following $\mathrm{SCl}$ are rather limited while the influence of neuropathic pain on plasticity remains controversial.
\end{abstract}




\section{Introduction}

Neuropathic pain (NP) represents a major secondary complication for people currently living with $\mathrm{SCI}$, negatively impacting quality of life and functional independence [56; 57]. Among difficulties related to the development of more effective interventions, mechanisms of NP are poorly understood. One prevailing theory is that NP from below the level of neurological injury arises from maladaptive changes in supraspinal anatomy and physiology $[9 ; 24 ; 44 ; 65 ; 66]$. Central to this theory is that the intensity of NP symptoms positively correlates with the extent of cortical reorganization, such that greater reorganization is observed in individuals with more severe NP [15;65]. In individuals with phantom limb pain, evidence of maladaptive plasticity has been largely demonstrated in primary sensorimotor areas following executed (contralateral to missing limb) or imagined (missing limb) movement [35; 36; 39; 53]. Supporting 'maladaptive plasticity', Wrigley and colleagues recently demonstrated that greater reorganization in the primary somatosensory cortex in response to brushing was associated with more severe neuropathic pain in individuals with SCI [65]. Previous studies in SCI have also considered reorganization in the primary motor cortex $[11 ; 27]$, although not in the context of NP (i.e., relationship between the extent of reorganization and the severity of pain symptoms). A common readout of cortical reorganization has been to measure changes in center of gravity (CoG) $[10 ; 22]$ or Euclidean distance between peak activity associated with a motor task or afferent stimulation (e.g., brushing, finger-tapping, etc.), relative to a known (and fixed) anatomical landmark [3; 23; 65].

The primary aim of the present study was to address the relationship between the intensity of NP and cortical reorganization after $\mathrm{SCl}$ in brain areas processing 
sensorimotor information. In line with phantom limb studies, we hypothesized that $\mathrm{SCl}$ would induce sensory and motor reorganization, the degree of which would be associated with the intensity of NP symptoms. Using functional magnetic resonance imaging (fMRI), individuals with $\mathrm{SCl}$ were examined during sensory stimulation (i.e., brushing and heat), and movement tasks (i.e., active and passive wrist extension). Based on the presence and intensity of individuals reported NP symptoms, the analysis focused on addressing group-level differences in activity, as well as changes in the location of peak activity (i.e., Euclidean distance) in primary sensory and motor areas. 


\section{Material and Methods}

\subsection{Subjects}

A total of 26 individuals with a chronic traumatic SCI (mean (SD) 46.3 (11.9) years; sex: 3 female, 23 male) including individuals with tetra- $(\mathrm{N}=11)$ and paraplegia $(\mathrm{N}=15)$ were recruited. Only individuals that could perceive brushing and heat stimulation applied on the C6 dermatome, as well as independently perform active wrist extension were included in the study. Two individuals with $\mathrm{SCl}$ (1 individual with tetraplegia and 1 with paraplegia) were excluded due technical measurement errors. Additionally, 31 neurologically healthy individuals (mean (SD) 31.9 (9.9) years; sex: 14 female, 17 male) were enrolled in the study. Participants' demographic and clinical details are summarized in Table 1. All participants provided written informed consent and all procedures described below were in accordance with the Declaration of Helsinki and approved by the local ethics board (ref. number: EK-04/2006).

Table 1. Demographic and clinical details of the sample

\begin{tabular}{|c|c|c|c|c|}
\hline \multirow[t]{2}{*}{ Parameter } & \multicolumn{3}{|c|}{ Groups } & \multirow[t]{2}{*}{$\begin{array}{l}\text { Significant pairwise } \\
\text { comparisons }\left(p<0.05^{\ddagger}\right)\end{array}$} \\
\hline & $\begin{array}{l}\text { Healthy } \\
\text { controls }\end{array}$ & $\begin{array}{l}\text { Tetraplegic } \\
\text { SCI }\end{array}$ & $\begin{array}{l}\text { Paraplegic } \\
\text { SCI }\end{array}$ & \\
\hline Gender [male : female] & $9: 12$ & $10: 0$ & $12: 2$ & Controls-tetraplegic SCI $(<0.001)$; Controls - paraplegic SCI $(<0.001)$ \\
\hline Age [yrs] & $31.9 \pm 9.9$ & $41.5 \pm 12.2$ & $45.2 \pm 9.94$ & Controls-tetraplegic SCI $(<0.001) ;$ Controls - paraplegic SCI $(=0.002)$ \\
\hline Handedness $^{\dagger}$ [right : left] & $30: 2$ & $9: 1$ & $14: 0$ & ns \\
\hline AIS motor score & $100 \pm 0$ & $64.2 \pm 30.1$ & $57.9 \pm 18.5$ & Controls-tetraplegic SCI $(<0.001)$; Controls - paraplegic SCI $(<0.001)$ \\
\hline AIS sensory score & $224 \pm 0$ & $159.4 \pm 47.5$ & $143.1 \pm 39.4$ & Controls-tetraplegic SCI $(<0.001)$; Controls - paraplegic SCI $(<0.001)$ \\
\hline Duration of $\mathrm{SCl}[\mathrm{yrs}]$ & & $11.0 \pm 7.3$ & $16.5 \pm 9.4$ & ns \\
\hline Injury severity [complete : incomplete] & & $2: 8$ & $9: 5$ & ns \\
\hline Neuropathic pain (yes : no) & & $4: 6$ & $8: 6$ & ns \\
\hline Duration of pain [yrs] ${ }^{*}$ & & $7.1 \pm 1.9$ & $16.1 \pm 8.2$ & ns \\
\hline Mean pain intensity* & & $4.1 \pm 1.9$ & $4.3 \pm 2.3$ & ns \\
\hline Max pain intensity* & & $4.9 \pm 2.9$ & $6.3 \pm 3.0$ & ns \\
\hline
\end{tabular}

Results are displayed as mean \pm standard deviation.

†: Bonferroni corrected

t: German version of the Edinburgh inventory questionnaire

*: EMSCl pain questionnaire with incorporated visual analogue scale ranging

from 0 (no pain) to 10 (worst pain imaginable). $y=y e s, n=n o$

SCl: Spinal cord injury 


\subsection{Clinical assessments}

Prior to the functional magnetic resonance imaging (fMRI), all participants were interviewed to determine handedness and the existence of pain using the German versions of the Edinburgh inventory (14 item version, [46]) and the European Multicenter Study about SCI (EMSCl) pain questionnaire (V4.2, http://www.emsci.org/), respectively. The pain questionnaire examines various aspects of pain (e.g., duration, maximal and average pain intensity) as well as pain associated psychosocial factors. Accordingly, pain can be grouped into nociceptive (e.g., musculoskeletal or visceral) or neuropathic pain (e.g., at or below the lesion). To be classified as below-neuropathic pain, symptoms (e.g., burning, cold, tingling) reported had to be located three or more segments below the neurological level of lesion. In individuals with $\mathrm{SCl}$, the neurological level of injury was assessed using the International Standards for Neurological Classification of Spinal Cord Injury published by the American Spinal Injury Association (ASIA) [4; 42; 43]. Briefly, sensory, motor, and neurological levels of injury were identified allowing characterization of sensory/ motor functioning as well as determination of the completeness of injury by means of the ISNCSCI Impairment Scale (AIS).

\subsection{Image acquisition}

MRI data was collected on a Philips $3 \mathrm{~T}$ Achieva system (Philips Medical Systems, Best, the Netherlands) using an eight-channel Philips Sense head coil. Functional time series were acquired with a sensitivity-encoded (reduction factor 2), single-shot echo-planar sequence (SENSE-sshEPI) [54] with a measured resolution of $2.75 \times 2.75 \times 4 \mathrm{~mm}$. The 29 axial slices without interslice gaps covered the entire cerebrum. Slices were aligned to the anterior commissure-posterior commissure line. Other scan parameters were as follows: echo time $=35 \mathrm{~ms}$; flip angle $=90^{\circ}$, repetition 
time $=3000$ s; field of view $=220 \times 135 \times 220 \mathrm{~mm}$; reconstruction matrix of scan resolution $72 \times 72$ voxels with $3 \times 3 \times 3 \mathrm{~mm}$, and scan time of $16: 12 \mathrm{~min}$. The first three scans were acquired to reach steady-state magnetization and then discarded. In total, 320 volumes were acquired.

A 3D-GRE T1-weighted (T1w) sequence was used to acquire a whole-brain, structural scan optimized for simultaneous assessment of the brain and spinal cord [17]. The imaging parameters were: isotropic $1 \mathrm{~mm}^{3}$ resolution, field of view $256 \times 256 \times 180$, repetition time $=6.88 \mathrm{~ms}$, echo time $=3.1 \mathrm{~ms}$, flip angle $8^{\circ}$, fat saturation, scan resolution 256x256 voxels, and a scan time of 6:31min. Prior to analysis the MRI data were screened for movement artefacts.

\subsection{Functional MRI paradigm}

The functional task comprised active 20s blocks of uni-lateral (i.e., right hand) active and passive wrist extension, heat stimulation, and brushing. Six repetitions of each task blocks were performed alternating with 20s rest blocks (starting with a rest block). The active blocks were presented in pseudo-randomized order (Figure 1).

All participants were scanned lying in a supine position and viewed visual stimuli projected screen via a mirror system mounted above the magnetic resonance head-coil. The right arm was secured to the MR bed only allowing the subject to execute the wrist extension following a physiological range of motion (i.e., range through which the wrist can be moved pain-free). In order to standardize sensory input, participants hold a handle in the hand during the entire time of scanning session (Figure 1). In addition, the strap attached to the handle was used to perform the passive wrist extension without touching the participant. During the passive wrist extension, the examiner extended the participants right hand-wrist along the physiological individual range of motion and then 


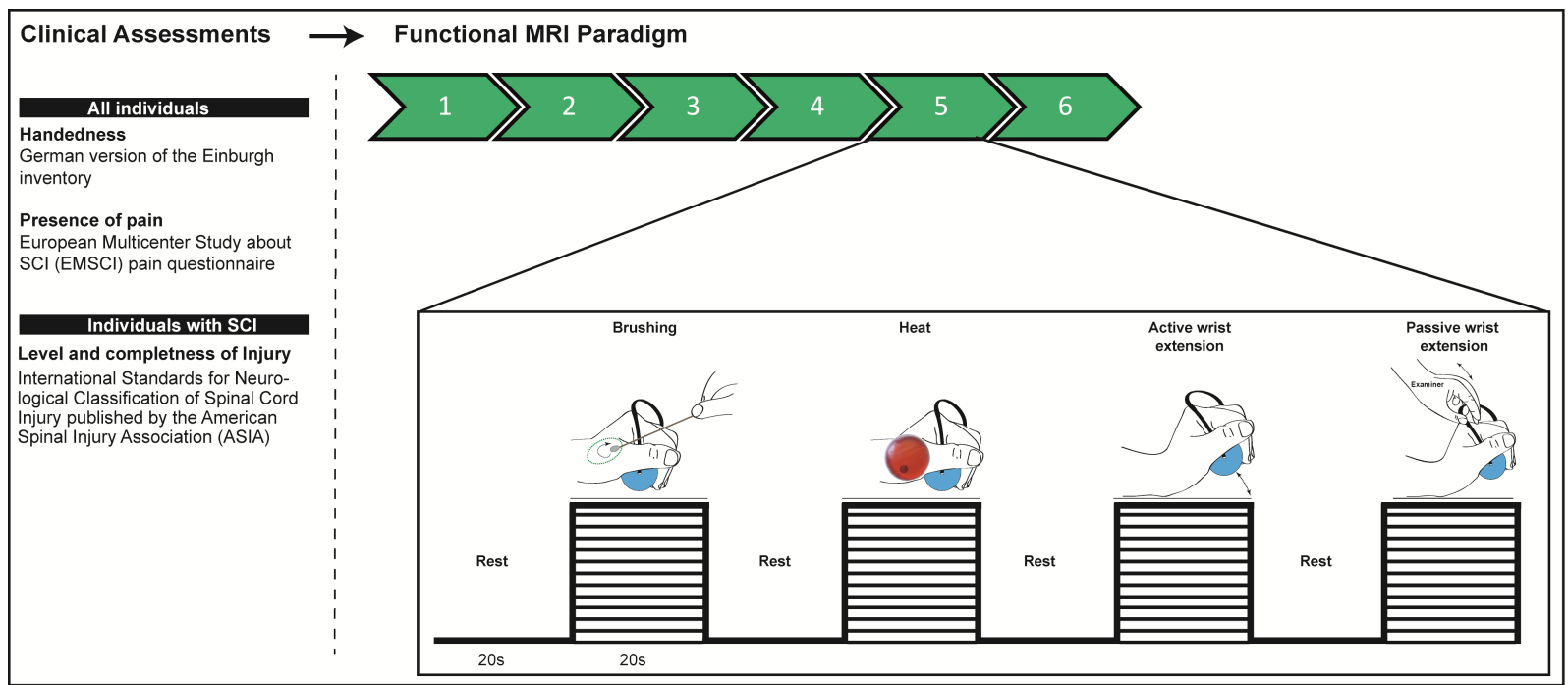

Figure 1: Study design: Prior to the functional magnetic resonance imaging (fMRI) paradigm the clinical assessments were conducted.All participants were interviewed to determine handedness and the existence of pain using the German
versions of the Edinburgh inventory (14 item version, [29)) and the European Multicenter Study about SCI (EMSCI) pain questionnaire (V4.2, http://www.emsci. org/), respectively. In individuals with SCI, the neurological level and the completness of the injury was also determined using the International Standards for Neurological Classification of Spinal Cord Injury published by the American Spinal Injury Association. Cortical activation was assessed in response to sensory and motor task. The functional paradigm was composed of active 20 s blocks of uni-lateral (i.e., right hand) brushing, heat stimulation, active and passive wrist extension. Six repetitions of each task blocks were performed alternating with 20 s res
blocks (starting with a rest block). The active blocks were presented in pseudo-randomized order. Heat stimulation and brushing were applied to the 66 dermatome. Active and passive wrist extensions were conducted 10 times/ block. In order to reduce the sensory input, a handle was used to execute the passive wrist extension. In order to correct for the sensory input of the handle, participants were holding it during the entire experiment.

brought it back to its original starting position using the strap [38;60;63]. For the active wrist extension task, participants were asked to actively extend their right wrist along the physiological range of motion and bring it back to the original starting position [27]. For both motor tasks, the hand was initially positioned in resting pronation, and was extended upward against gravity with a cadence of 10 movements/ block (i.e., $2 \mathrm{~Hz}$ ). Each subject practiced this cadence prior to entering the scanner. Heat stimulation comprised of placing heat packs (average temp: $52.3^{\circ} \mathrm{C}$; Trevolution, Zurich, Switzerland) onto the right C6 dermatome for 20s [14;30]. A new heat pack was used for each 20s block. Brushing involved consistently brushing the right $\mathrm{C} 6$ dermatome with cotton swabs $[51 ; 55 ; 65]$. Brushing was performed at the base of the thumb. Importantly, the area of brushing did not overlap with the area of heating. For both sensory tasks, participants were instructed to lie quietly and minimize the eyemovement.

\subsection{Validation of the temperature of the heat packs}

Fourteen reusable heat packs contain a supersaturated solution of sodium acetate $(3 \mathrm{H} 2 \mathrm{O} \mathrm{CH} 3 \mathrm{COONa})$ in water were tested. The heat pack is activated by 
triggering the crystallization of the sodium acetate by bending a small flat disc of notched ferrous metal embedded in the liquid. To account for the effect of the room temperature on the temperature of the heat pack, the validation study was conducted in at similar room temperature (i.e., $21^{\circ} \mathrm{C}$ ) as in the MRI Scanner. Heat packs were tested twice, on two separate days by the same examiner (CRJ). The temperatures of the heat packs were assessed using the YSI 4600 Series Precision Thermometers (YSI Incorporated). The temperature was considered stable when the peak reading did not change for two minutes. This procedure was repeated twice and the averaged was calculated. Additionally, we determined the time it takes from initiating the crystallization until the stable temperature was reached.

\subsection{MRI Data Analysis}

Functional volumes were preprocessed and analyzed in Matlab 2010b using Statistical Parametric Mapping 8 (SPM8) (http://www.fil.ion.ucl.ac.uk/spm/software/spm8). The images were initially realigned to the first scan and unwarped to control for movement- and susceptibility-induced image distortions [1]. Movement parameter were calculated to be later included in the statistical model. Following coregistration of the anatomical and functional images, spatial normalization of the functional images was executed. Using a unified segmentation approach, individual brains were normalized to the Montreal Neurological Institute standard space (MNI space). Lastly, spatial smoothing was conducted by applying an isotropic 8-mm full-width-at-half-maximum (FWHM) Gaussian kernel to reduce image noise.

A voxel-wise general mixed model was used for the first-level analysis (i.e., within a subject) in order to calculate contrast images for each task separately (i.e., heat, 
brushing, active and passive wrist extension). Vectors of motion estimates were included as 'nuisance variables' (covariates of no interest) to account for the variance due to motion in the GLMs [26]. Significant increases in BOLD signal were identified using a repeated box car model convolved with a canonical form of the hemodynamic response function [19]. The second-level analysis (i.e., group analysis) was performed to identify task-specific pattern of activation for each group (i.e., healthy controls, individuals with paraplegia, and individuals with tetraplegia). Significant differences between the control and $\mathrm{SCl}$ groups, between $\mathrm{SCl}$ without pain and $\mathrm{SCl}$ with pain groups during each task were also determined. Age, sex, level of lesion, and total intracranial volume (TIV) were included in the model as nuisance variables. All results reported were corrected for multiple-comparisons using the family-wise error (FWE).

For group comparisons, whole-brain analyses as well as region of interest (ROI) analyses were computed. The whole brain analysis was conducted for a comprehensive overview. Additionally, the ROI approach was performed to explore regional differences in task-related brain activation between all the groups. Thus, the ROls were included as a mask in order to restrict the voxel-by-voxel statistical analysis (including FWEcorrection) to pre-specified brain areas [52]. These ROls incorporated primary (S1) and secondary (S2) somatosensory cortices, primary motor cortex (M1), premotor cortex (PMC), supplementary motor area (SMA), thalamus, anterior cingulate cortex (ACC), and cerebellum and were generated using the WFU Pickatlas [33; 41]. The rational for the selected ROls stemmed from all areas mainly being involved in the encoding and processing of either motor output (M1, PMC, SMA, and cerebellum) or sensory input (S1, S2, thalamus, ACC) $[12 ; 50]$. 


\subsection{Euclidean Distance}

The point at which the central sulcus meets the longitudinal fissure at the dorsal aspect of the brain was set as anatomical marker [65]. The Euclidean distance (ED) between the anatomical marker and the maximally activated voxel in task-specific ROls (i.e., S1 for heat/brushing, M1 for active/passive wrist extension) was computed for the anterior-posterior, medial-lateral and superior-inferior coordinates. The ED between two points in a plane is calculated with the Pythagorean theorem and provides an absolute value independently of direction [18].

\subsection{Statistics}

All statistical procedures were performed using IBM`s Statistical Package for the SocialSciences (SPSS) version 19.0 (Armonk, New York, U.S.). Non-parametric tests (Mann-Whitney-U and Kruksal-Wallis) were applied to determine significant differences in ED, peak activation, and cluster size between healthy controls, individuals with $\mathrm{SCl}$ and an intact $\mathrm{C} 6$ dermatome, as well as individuals with $\mathrm{SCl}$ and an impaired $\mathrm{C} 6$ dermatome. Pain-specific changes of ED, peak activation, and cluster size were explored by comparing the control group with the neuropathic pain $\mathrm{SCl}$ group as well as the pain-free $\mathrm{SCl}$ group. $\mathrm{P}<0.05$ was considered significant. All multiple comparisons were Bonferroni corrected. Spearman correlation was applied to assess the relationship of EDs and pain parameters (e.g., intensity, duration). Level of lesion and injury severity (i.e., AIS score) were included as covariates.

Contrast estimates of all ROls from the $\mathrm{SCl}$ patients were extracted in order to perform Spearman correlations to identify associations between task-specific cortical activation and clinical characteristics (i.e., SCA, AIS motor and sensory scores, disease duration, level of lesion, pinprick and light touch scores, as well as pain intensity and duration). 


\section{Results}

\subsection{Injury and pain characteristics, subject demographics}

Of the 28 individuals with SCI, 11 had AIS complete (2 tetraplegic, 9 paraplegic) and 17 incomplete (12 tetraplegic, 5 paraplegic) injuries. In total, 13 patients (8 with paraplegia, 5 with tetraplegia) reported neuropathic pain (NP) (Table 2). The mean and maximal pain intensities were $4.5 \pm 3.1$ and $5.2 \pm 3.8$, respectively, and the duration of ongoing pain ranged from 4 to 33 years (mean $17.5+/-12.3$ years).

Table 2. Clinical data for the spinal cord injured individuals

\begin{tabular}{|c|c|c|c|c|c|c|c|c|c|}
\hline ID & Age [yrs] & Gender & $\begin{array}{l}\text { Etiology } \\
\text { of the injury }\end{array}$ & $\begin{array}{c}\text { Time since Injury } \\
\text { [yrs] }\end{array}$ & $\begin{array}{l}\text { Level of } \\
\text { Lesion }{ }^{\ddagger}\end{array}$ & AlS* & $\begin{array}{l}\text { Motor } \\
\text { score } \\
(0-100)\end{array}$ & $\begin{array}{c}\text { Sensory } \\
\text { score } \\
(0-224)^{+}\end{array}$ & $\begin{array}{c}\text { Neuropathic } \\
\text { pain }\end{array}$ \\
\hline \multicolumn{10}{|c|}{ Individuals with paraplegic SCI } \\
\hline P01 & 50 & $\mathrm{~m}$ & Vehicle accident & 7 & Th4/Th5 & A & 50 & 90 & Below-level \\
\hline P02 & 50 & $\mathrm{~m}$ & Vehicle accident & 9 & Th4 & B & 50 & 200 & no \\
\hline P03 & 35 & $\mathrm{~m}$ & Gunshot & 12 & Th4 & $\mathrm{B}$ & 50 & 144 & Below-level \\
\hline P04 & 48 & $\mathrm{~m}$ & Vehicle accident & 16 & Th6/7 & $A$ & 50 & 112 & Below-level \\
\hline P05 & 44 & $\mathrm{~m}$ & Vehicle accident & 26 & Th7 & $\mathrm{B}$ & 50 & 168 & Below-level \\
\hline P06 & 44 & $\mathrm{~m}$ & Gun shot & 17 & Th6 & $A$ & 50 & 96 & no \\
\hline P07 & 29 & $\mathrm{~m}$ & Sports accident & 14 & Th11 & $A$ & 50 & 128 & Below-level \\
\hline P08 & 38 & $\mathrm{~m}$ & Vehicle accident & 16 & Th8 & $A$ & 50 & 104 & no \\
\hline P09 & 29 & $f$ & Sports accident & 5 & L3 & $\mathrm{D}$ & 100 & 217 & Below-level \\
\hline P10 & 65 & $\mathrm{~m}$ & Vehicle accident & 33 & Th12 & $A$ & 50 & 158 & Below-level \\
\hline P11 & 60 & $\mathrm{~m}$ & Vehicle accident & 2 & Th12 & $\mathrm{D}$ & 100 & 185 & no \\
\hline P12 & 50 & $\mathrm{~m}$ & Vehicle accident & 4 & Th11 & $A$ & 60 & 148 & no \\
\hline P13 & 43 & $\mathrm{~m}$ & Vehicle accident & 24 & Th6 & A & 50 & 110 & no \\
\hline P14 & 48 & $f$ & Hit by tree & 19 & L1 & A & 50 & 144 & Below- / at-level \\
\hline \multicolumn{10}{|c|}{ Individuals with tetraplegic SCI } \\
\hline T01 & 25 & $\mathrm{~m}$ & Sports accident & 2 & $\mathrm{C} 6 / \mathrm{C} 7$ & $\mathrm{D}$ & 71 & 134 & no \\
\hline T02 & 39 & $\mathrm{~m}$ & Vehicle accident & 20 & $\mathrm{C} 6$ & C & 38 & 126 & no \\
\hline T03 & 53 & $\mathrm{~m}$ & Gun shot & 10 & $\mathrm{C} 8$ & B & 30 & 165 & no \\
\hline T04 & 57 & $\mathrm{~m}$ & Vehicle accident & 6 & $\mathrm{C} 6 / \mathrm{C} 7$ & $\mathrm{D}$ & 96 & 202 & Below-level \\
\hline T05 & 40 & $\mathrm{~m}$ & Vehicle accident & 19 & $\mathrm{C} 6$ & $\mathrm{~B}$ & 24 & 78 & no \\
\hline T06 & 50 & $\mathrm{~m}$ & Vehicle accident & 27 & $\mathrm{C} 6 / \mathrm{C} 7$ & $A$ & 30 & 83 & no \\
\hline & 35 & $\mathrm{~m}$ & Sports accident & 5 & $\mathrm{C} 6 / \mathrm{C} 7$ & $\mathrm{D}$ & 93 & 176 & no \\
\hline T07 & 40 & $\mathrm{~m}$ & Vehicle accident & 10 & C7 & $\mathrm{D}$ & 96 & 160 & Below-level \\
\hline T08 & 24 & $\mathrm{~m}$ & Vehicle accident & 7 & $\mathrm{C} 6 / \mathrm{C} 7$ & $A$ & 40 & 185 & no \\
\hline T09 & 65 & $\mathrm{~m}$ & Vehicle accident & 9 & C6 & $\mathrm{D}$ & 88 & 220 & Below-level \\
\hline T10 & 40 & $\mathrm{~m}$ & Vehicle accident & 6 & $\mathrm{C} 7$ & $\mathrm{D}$ & 100 & 224 & Below-level \\
\hline
\end{tabular}

$\ddagger$ : The level of lesion refers to the neurological level

*ASIA impairment scale: $A$, no sensory or motor function is preserved; $B$, sensory function is preserved below the level of the injury, but there is no motor function; $\mathrm{C}$, motor function is preserved below the neurological level, and more than half of the key muscles below the neurological level have a muscle grade of $<3$; D, motor function is preserved below the neurological level, and at least half of the key muscles below the neurological level have a muscle grade of $>3$.

+Sensory Score: Sum of segmental light touch and pinprick classifications 


\subsection{Validation of the temperature of heat packs}

From a total of 14 heat packs evaluated two were excluded because the average temperature did significantly differ from the other heat packs as the temperatures did not reach $50^{\circ} \mathrm{C}$ (i.e., 49.2 and $48.6^{\circ} \mathrm{C}$ ) and the time to reach the stable temperature was longer than 20s. The temperatures of the remaining 12 heat packs averaged at $52.3^{\circ} \mathrm{C} \pm$ $0.4^{\circ} \mathrm{C}$ (range $51.8-53.1^{\mathrm{C}}$ ). The measured average $t$ emperature is in line with the vendor's specification (Trevolution by MIGROS, Switzerland, http://www.sportxx.ch/de/trevolution-shop). The time between initiating the crystallization and reaching the stable temperature ranged from 10 to $13 \mathrm{~s}$.

\subsection{Patterns of brain activation in response to brushing, heat stimulation, active and passive wrist extension}

There were no task-related activation differences between $\mathrm{SCl}$ and healthy controls (Figure 2). Active and passive wrist extension evoked significant increases in signal intensity in contralateral primary motor cortex, primary and secondary sensory cortex, premotor cortex, and cerebellum. Heat and brushing stimulation resulted in significant signal intensity increases in left (heat and brushing) and right secondary sensory cortex (heat only), and left primary somatosensory cortex (brushing only) (Table 3). 


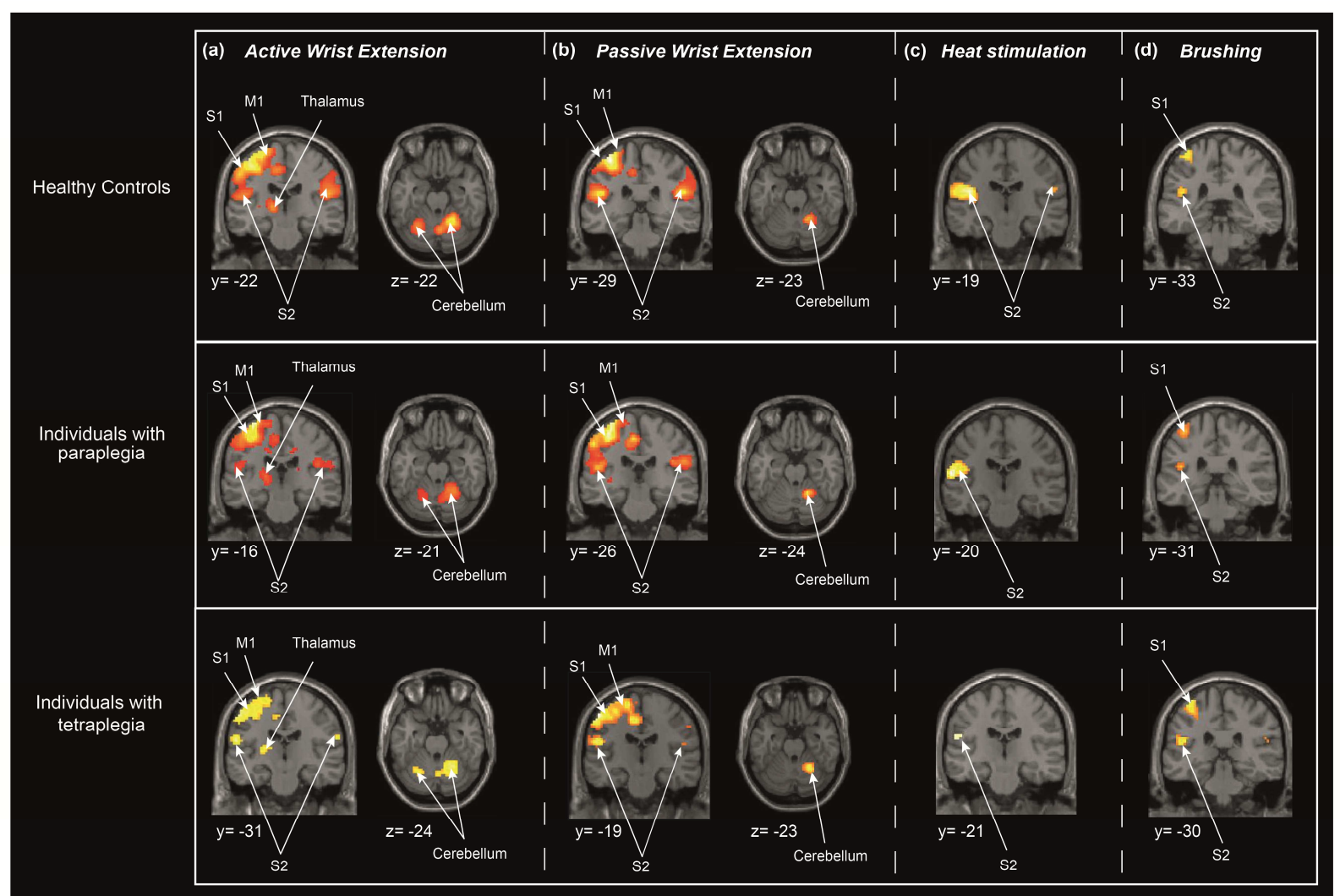

Figure 2: Task-specific brain activations in healthy controls, individuals with paraplegia, and individuals with tetraplegia. (a) Active wrist extension evoked BOLD signal increase in M1, S1, and thalamus (unilateral), as well as S2 and cerebellum (bilateral). (b) Similar areas were significantly activated during passive wrist extension with the exception of unilateral signal increase in cerebellum. (c) Heat and (d) brushing stimulation resulted in significant signal intensity increases in left (heat and brushing) and right secondary sensory cortex (heat only), and left primary somatosensory cortex (brushing only).

S1: Primary sensory cortex; S2: Secondary sensory cortex; M1: Primary motor cortex 
Table 3: Cortical and subcortical areas activated in response to active and passive wrist extension, heat stimulation, and brushing. Areas, cluster size, Z- and T-values, and MNI coordinates are listed for healthy controls and individuals with SCI.

\begin{tabular}{|c|c|c|c|c|c|c|c|c|}
\hline \multirow{2}{*}{ Groups } & \multirow{2}{*}{ Area } & \multirow{2}{*}{$\begin{array}{l}\text { P-value } \\
\text { (FWE- } \\
\text { corrected) }\end{array}$} & \multirow{2}{*}{ Z-Value } & \multirow{2}{*}{ T-Value } & \multirow{2}{*}{$\begin{array}{l}\text { Cluster } \\
\text { size }\end{array}$} & \multicolumn{3}{|c|}{$\begin{array}{c}\text { Coordinates in MNI } \\
(\mathrm{mm})\end{array}$} \\
\hline & & & & & & $x$ & $y$ & $z$ \\
\hline \multicolumn{9}{|c|}{ Active wrist extension } \\
\hline \multirow[t]{6}{*}{ Controls } & M1 (I) & $<0.001$ & $>8$ & 19.29 & 151 & -36 & -31 & 61 \\
\hline & S1 (I) & $<0.001$ & $>8$ & 20.00 & 158 & -36 & -34 & 61 \\
\hline & S2 (I) & $<0.001$ & 6.67 & 10.26 & 123 & -48 & -28 & 19 \\
\hline & PMC (I) & $<0.001$ & $>8$ & 17.12 & 902 & -33 & -28 & 67 \\
\hline & Cerebellum (I) & $<0.001$ & 6.5 & 9.76 & 150 & -27 & -58 & -26 \\
\hline & Cerebellum (r) & $<0.001$ & 7.66 & 13.71 & 342 & 18 & -52 & -23 \\
\hline \multirow{6}{*}{$\begin{array}{l}\text { Individuals with } \\
\mathrm{SCl}\end{array}$} & M1 (I) & $<0.001$ & 6.75 & 11.08 & 117 & -36 & -31 & 67 \\
\hline & S1 (I) & $<0.001$ & 6.49 & 10.23 & 96 & -36 & -34 & 55 \\
\hline & S2 (I) & $<0.001$ & 5.74 & 8.16 & 48 & -48 & -31 & 22 \\
\hline & PMC (I) & $<0.001$ & 6.63 & 10.69 & 568 & -36 & -28 & 67 \\
\hline & Cerebellum (I) & $<0.001$ & 4.99 & 6.48 & 35 & -24 & -61 & -23 \\
\hline & Cerebellum (r) & $<0.001$ & 6.20 & 9.37 & 267 & 27 & -49 & -26 \\
\hline \multicolumn{9}{|c|}{ Passive wrist extension } \\
\hline \multirow[t]{5}{*}{ Controls } & M1 (I) & $<0.001$ & $>8$ & 20.93 & 129 & -36 & -31 & 61 \\
\hline & S1 (I) & $<0.001$ & $>8$ & 20.30 & 136 & -36 & -34 & 61 \\
\hline & S2 (I) & $<0.001$ & 7.81 & 14.40 & 131 & -51 & -28 & 19 \\
\hline & PMC (I) & $<0.001$ & $>8$ & 18.55 & 885 & -36 & -28 & 67 \\
\hline & Cerebellum (r) & $<0.001$ & 7.20 & 11.97 & 161 & 18 & -52 & -20 \\
\hline \multirow{5}{*}{$\begin{array}{l}\text { Individuals with } \\
\mathrm{SCl}\end{array}$} & M1 (I) & $<0.001$ & 7.50 & 14.05 & 119 & -36 & -31 & 67 \\
\hline & $\mathrm{S} 1(\mathrm{I})$ & $<0.001$ & 7.28 & 13.09 & 112 & -36 & -34 & 61 \\
\hline & S2 (I) & $<0.001$ & 6.91 & 11.67 & 97 & -45 & -28 & 19 \\
\hline & PMC (I) & $<0.001$ & 7.63 & 14.64 & 794 & -33 & -28 & 67 \\
\hline & Cerebellum (r) & $<0.001$ & 6.72 & 10.99 & 116 & 24 & -52 & -23 \\
\hline \multicolumn{9}{|l|}{ Heat stimulation } \\
\hline \multirow[t]{3}{*}{ Controls } & S1 (I) & 0.005 & 4.13 & 5.84 & 12 & -33 & -31 & 61 \\
\hline & S2 (I) & $<0.001$ & 7.25 & 12.15 & 212 & -42 & -19 & 19 \\
\hline & $\mathrm{S} 2(\mathrm{r})$ & $<0.001$ & 5.0 & 6.31 & 7 & 57 & -19 & 22 \\
\hline \multirow{3}{*}{$\begin{array}{l}\text { Individuals with } \\
\mathrm{SCl}\end{array}$} & S1 (I) & 0.013 & 4.12 & 5.1 & 8 & -34 & -30 & 60 \\
\hline & S2 (I) & $<0.001$ & 4.79 & 8.21 & 97 & -60 & -16 & 13 \\
\hline & $\mathrm{S} 2(\mathrm{r})$ & $<0.001$ & 4.1 & 6.2 & 4 & 54 & -19 & 23 \\
\hline \multicolumn{9}{|l|}{ Brushing } \\
\hline \multirow[t]{2}{*}{ Controls } & S1 (I) & $<0.001$ & 5.57 & 7.45 & 7 & -57 & -16 & 37 \\
\hline & S2 (I) & $<0.001$ & 6.97 & 11.19 & 119 & -48 & -25 & 19 \\
\hline \multirow{2}{*}{$\begin{array}{l}\text { Individuals with } \\
\mathrm{SCl}\end{array}$} & S1 (I) & $<0.001$ & 6.17 & 9.30 & 16 & -39 & -34 & 58 \\
\hline & S2 (I) & $<0.001$ & 6.31 & 9.70 & 95 & -54 & -19 & 22 \\
\hline
\end{tabular}

FWE: Family-wise error; S1: primary somatosensory cortex; S2: secondary somatosensory cortex; M1: primary motor cortex; PMC: premotor cortex; I: left; r: right; MNI: Montreal Neurological Institute; SCI: spinal cord injury 


\subsection{Shifts in primary somatosensory and primary motor cortices topography}

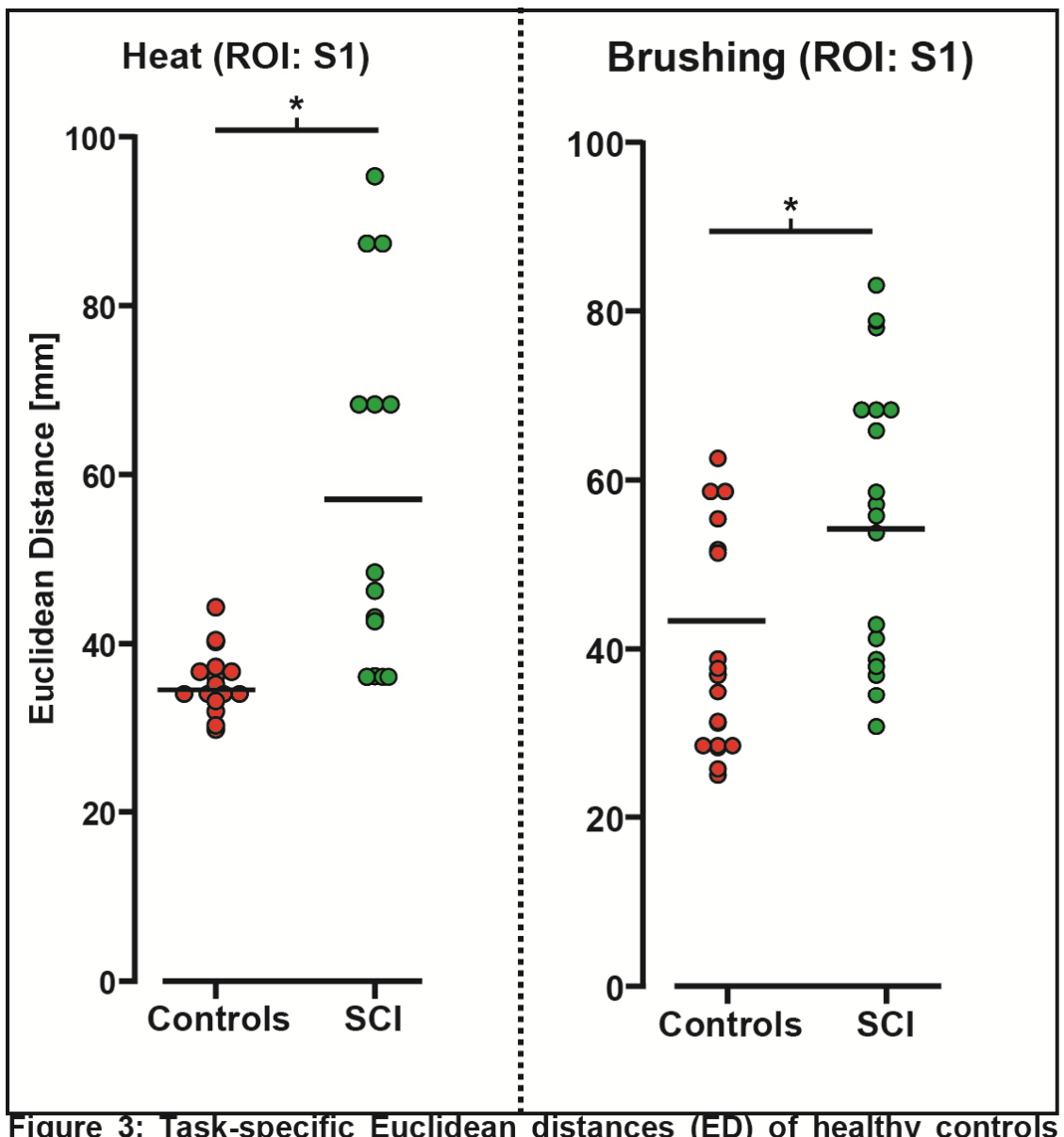

and individuals with SCI. Significant differences in EDs for heat, brushing were found in individuals with spinal cord injury $(\mathrm{SCl})$ when compared to the control group. Selected region of interest (ROI) was for both tasks the primary sensory cortex.

S1: Primary sensory cortex
Although the pattern of the taskspecific brain activation was similar across the group, there were significant differences in the location of peak activation. $\ln$

individuals with $\mathrm{SCl}$ compared to control subjects, the analysis yielded significant differences in ED for heat and brushing (Figure 3), as well as for active movement (Figure 4a). In control subjects, the mean $( \pm S D) X, Y, Z$ co-ordinates for active wrist extension: $-33 \pm 2.8,-28.8$ $\pm 2.8,60.7 \pm 5.7$; passive wrist extension: $-33.8 \pm 2.5,-27.9 \pm 10.5,63.9 \pm 5.0$; heat stimulation: $-33.7 \pm 3.1,-30.5 \pm 6.4,61.0 \pm 4.0$; brushing: $-39.2 \pm 9.6,-31.3 \pm 8.5,58.9 \pm$ 10.0. These coordinates yielded mean ED of $35.7 \pm 3.3 \mathrm{~mm}, 36.3 \pm 7.0 \mathrm{~mm}, 35.9 \pm 3.6$ $\mathrm{mm}$, and $42.5 \pm 12.6 \mathrm{~mm}$ for active wrist extension, passive wrist extension, heat stimulation, and brushing, respectively. In individuals with $S C I$, the mean $( \pm S D) X, Y, Z$ 
co-ordinates for active wrist extension were $-38.9 \pm 4.7,-24.0 \pm 4.3,58.5 \pm 4.7$; passive wrist extension: $-35.0 \pm 2.7,-27.9 \pm 2.8,60.5 \pm 5.8$; heat stimulation: $-46.6 \pm 11.4,-17.7$ $\pm 18.4,44.1 \pm 16.2$; and brushing: $-46.9 \pm 11.4,-21.5 \pm 8.4,43.7 \pm 10.3$ (respectively). The mean ED between the anatomical marker and the MNI co-ordinates for active wrist extension were $42.2 \pm 5.8 \mathrm{~mm}$; passive wrist extension $37.5 \pm 3.11 \mathrm{~mm}$; heat stimulation $56.1 \pm 22.2 \mathrm{~mm}$, brushing $55.9 \pm 16.8 \mathrm{~mm}$ (Table 4). Pain-related changes in ED were found for primary motor cortex during the active wrist extension task (Figure 4b). While pain-free individuals with $\mathrm{SCl}$ exhibit an increase in ED compared to healthy controls, the ED of individuals with $\mathrm{SCl}$ reporting neuropathic pain did not differ from healthy control values. In pain-free individuals with $S C I$, the mean $( \pm S D) X, Y, Z$ co-ordinates were active wrist extension: $-35.7 \pm 4.2,-26.0 \pm 3.4,59.3 \pm 3.7$, and the mean ED Table 4. Euclidean Distances and coordinates.

\begin{tabular}{|c|c|c|c|c|c|}
\hline \multirow[t]{2}{*}{ Groups } & \multirow{2}{*}{$\begin{array}{l}\text { Euclidean } \\
\text { distance } \\
(\mathrm{mm})\end{array}$} & \multicolumn{3}{|c|}{$\begin{array}{c}\text { Coordinates in MNI } \\
(\mathrm{mm})\end{array}$} & \multirow{2}{*}{$\begin{array}{l}\text { Significant pairwise } \\
\text { comparisons }(p<0.05 \ddagger)\end{array}$} \\
\hline & & $\mathrm{x}$ & $\mathrm{y}$ & $\mathrm{z}$ & \\
\hline Controls & $35.7 \pm 3.3$ & $-33 \pm 2.8$ & & & $\begin{array}{l}\text { Controls - Individuals with SC } \\
\qquad(\mathrm{p}<0.05)\end{array}$ \\
\hline \multicolumn{6}{|l|}{ Passive wrist extension } \\
\hline Controls & $36.3 \pm 7.0$ & $-33.8 \pm 2.5$ & $-27.9 \pm 10.5$ & $63.9 \pm 5.0$ & \multirow[b]{2}{*}{ n.s. } \\
\hline Individuals with SCI & $37.5 \pm 3.11$ & $-35.0 \pm 2.7$ & $-27.9 \pm 2.8$ & $60.5 \pm 5.8$ & \\
\hline \multicolumn{6}{|l|}{ Brushing } \\
\hline Controls & $42.5 \pm 12.6$ & $-39.2 \pm 9.6$ & $-31.3 \pm 8.5$ & $58.9 \pm 10.0$ & \multirow{2}{*}{$\begin{array}{l}\text { Controls - Individuals with SC } \\
\qquad(\mathrm{p}<0.05)\end{array}$} \\
\hline Individuals with SCI & $55.9 \pm 16.8$ & $-46.9 \pm 11.4$ & $-21.5 \pm 8.4$ & $43.7 \pm 10.3$ & \\
\hline
\end{tabular}

Results are displayed as mean \pm standard deviation.

t: Bonferroni corrected

$\mathrm{MNI}=$ Montreal Neurological Institute

n.s. = not significant

between the anatomical marker and the $\mathrm{MNI}$ co-ordinates were active wrist extension 
$37.7 \pm 2.8 \mathrm{~mm}$. In individuals with $\mathrm{SCl}$ suffering from $\mathrm{NP}$, the mean $( \pm \mathrm{SD}) \mathrm{X}, \mathrm{Y}, \mathrm{Z}$ coordinates were active wrist extension: $-35.1 \pm 4.5,-26.1 \pm 4.6,57.8 \pm 5.4$; and the mean ED between the anatomical marker and the $\mathrm{MNI}$ co-ordinates were active wrist extension $40.5 \pm 3.8 \mathrm{~mm}$. Based on the classification with NP, EDs for brushing, heat stimulation, and passive movement were not significantly different.

\subsection{Correlation with pain intensity and other variables}

The correlation between topographical shifts in primary motor cortex during active wrist extension and the intensity of chronic NP is illustrated in Figure 4c. The magnitude of cortical reorganization of primary motor cortex during active wrist extension negatively correlated with the intensity of ongoing neuropathic pain, such that shifts in peak activation were less pronounced in individuals with more severe NP compared to individuals with less severe NP. A sensitivity analysis indicated that the level and severity of injury had no impact on the correlation. No significant correlations were found between the ongoing pain and the task-specific brain activation during passive movement, heat stimulation, and brushing. 


\section{Discussion}

Applying $\mathrm{fMRI}$, the current study assessed reorganization in brain areas involved in processing sensorimotor information after $\mathrm{SCl}$. Furthermore, the study aimed at determining if neuropathic pain constitutes a contributing factor for the observed plasticity. In line with investigations in phantom limb pain, we were primarily interested to examine primary motor cortex (M1) reorganization in response to movement, executed above the level of injury (i.e., intact spinal segments) [35; 40]. In response to $\mathrm{SCl}$, topographical shifts in peak activity were observed following sensory stimulation (brushing and heat in primary somatosensory), as well as active movement (primary motor cortex). Interestingly, peak activation topography in response to wrist extension was significantly shifted to a greater extent in pain-free individuals compared to healthy controls and individuals with NP. A correlation analysis in individuals with NP revealed a significant negative relationship, such that larger topographical shifts in primary motor cortex were associated with less reported chronic neuropathic pain (i.e., individuals with higher NP intensities were more similar to healthy controls). In addition to demonstrating reorganization after $\mathrm{SCl}$, these novel findings indicate that $\mathrm{NP}$ may preserve functional cortical topography.

\subsection{Preserved functional organization associated with neuropathic pain}

In agreement with previous studies, deafferentation due to $\mathrm{SCl}$ was shown to induce changes in the topographical organization of primary sensory and motor cortices [20;21;24; 27; 28; 62]. In contrast to Wrigley et al. [65], our findings suggest that cortical reorganization is dependent on individuals not reporting the presence of NP. This observation is further supported by a negative correlation between NP intensity and topographical shifts in primary motor cortex, indicating that individuals with more severe 
NP are more similar to healthy controls than pain-free individuals (Figure 4c). The negative correlation we observed in primary motor cortex contrasts the maladaptive plasticity model, which fundamentally states that greater cortical reorganization is associated with more severe pain symptoms $[15 ; 16 ; 51 ; 58 ; 65]$.

Makin and colleagues recently demonstrated the need to revisit the relationship between pain and cortical organization, demonstrating intact functional and structural representations of the hand in amputees with phantom limb pain [40]. Pain was postulated to replace peripheral afferent input resulting from amputation, contributing to "maintained cortical representation" of the missing hand. Similar to amputation, cortical organization of the hand in primary motor area after SCI may be preserved by painful sensory input arising from areas of the body deafferented by damage in the spinal cord. Such an interpretation inherently suggests that preserved functional organization in primary motor cortex is a consequence of neuropathic pain. Conversely, cortical reorganization could also be preventing the development of neuropathic pain after $\mathrm{SCl}-$ a form of adaptive plasticity. In such a case, reorganization in primary motor cortex is protective and the failure to reorganize is maladaptive.

Interestingly, we did not observe an effect of injury severity (i.e., completeness, lesion level, as well as AIS motor and sensory scores) on cortical reorganization. On one hand, this finding conflicts with the idea that residual sensation below the level of injury (i.e., NP) preserves functional activity in the brain. Several factors could explain why NP but not other forms of sensory sparring maintained cortical organization. First, clinical methods to assess residual sensory and motor sparing below the level of lesion may not be sensitive to detect subtle differences in injury severity. According to the ISNCSCI, 
residual sensation (light touch and pinprick) is only examined using a 3-point scale (0absent, 1-impaired, and 3-normal). Second, the intensity and persistence of below-level NP may represent greater afferent input compared to other residual sensation. In turn, chronic pain places higher demands on cortical structures, both ascending and descending, and thus has a greater impact on function.

\subsection{The primary motor cortex and NP}

Several studies in individuals with amputations have investigated the relationship between reorganization in primary motor cortex and phantom limb pain $[13 ; 15 ; 35 ; 40]$. Supporting the concept of maladaptive plasticity, evidence of functional reorganization in primary motor cortex has emerged from imagined and executed movement of the missing hand, and executed movement of the opposing (intact) hand [13;16;36; 39]. In healthy subjects, the primary motor cortex has been ascribed a role in processing normal responses to experimental noxious stimuli [29; 59]. Suggesting a role in antinociception, projections from the motor cortex to the periaqueductal gray matter have been elucidated in naïve rats [47]. Indicative of a role in chronic pain, targeting the primary motor cortex with neuromodulatory therapies (e.g., repetitive transcranial magnetic stimulation of the primary motor cortex) has proven effective in the relief of some NP symptoms in patient populations $[25 ; 34 ; 61]$. Based on our findings, one potential avenue for therapeutic benefit of neuromodulatory therapies targeting primary motor cortex could be the induction of "adaptive plasticity" in individuals with NP. The responsiveness of peak topography shifting towards "normal deafferentation" organization in primary motor cortex is a potential avenue for future research. 


\subsection{Task-related activation of distinct brain areas}

In line with previous studies, our active and passive motor tasks elicited increased BOLD responses in the primary motor cortex, premotor cortex, primary sensory cortex, supplementary motor area, and cerebellum (active motor task only) [32; 37; 38]. The brushing task resulted in significant signal increases in the primary and secondary cortices $[8 ; 65]$. In line with previous studies, the secondary somatosensory cortex was also consistently active in response to noxious thermal stimulation [8; 49]. At a group level, however, activation in other prominent areas (e.g., thalamus, insula, and anterior cingulate) was not observed in response to noxious heat. A number of factors may explain why we did not observe activation in these areas, including methodological differences between studies. For example, in the current study, we applied a thermal stimulus using commercially available heat packs for 20 seconds, which nominally reached $\sim 53^{\circ} \mathrm{C}$. In general, our protocol involves longer duration and higher temperature, and a greater number of stimulation blocks $(n=6)$ than comparable studies applying contact heat $[2 ; 6-8 ; 45]$. Due to repeated presentation of stimuli (noxious and non-noxious), activation in some brain areas (e.g., thalamus and ACC) may have been attenuated by habituation [2].

\subsection{Limitations}

In contrast to previous studies, we found no evidence for shifts primary somatosensory cortex (S1) topography related to the presence and intensity of NP during brushing in individuals with $\mathrm{SCl}$ compared to healthy control subjects [65]. Wrigley and colleagues found that the extent of cortical reorganization was associated with NP in response to brushing of the little finger, but not the thumb [65]. The present 
study examined only the base of the thumb using different sensory modalities, and thus did not address reorganization in response to stimulation in other areas (e.g., little finger, lip). Also compared with Wrigley, a limitation of our study is the heterogeneity of the SCI sample, which included both individuals with tetra- and paraplegia, as well as all severities of injury [65]. While our statistical analysis took these differences into account, a more powerful study design may be required to examine the interaction between pain and specific injury characteristics. On the other hand, it is important to consider that NP after $\mathrm{SCl}$ is not related to level or injury severity [57], thus a heterogeneous sample is potentially more reflective of the clinical condition. Furthermore, we accounted for the variability between individuals with $\mathrm{SCl}$ and healthy volunteers by explicitly modeling the linear variance of age, sex, level of lesion, and total intracranial volume (TIV) in all GLM analyses. [5; 48]. Due to the small and heterogenetic sample size, weak effects may not have been detected. However, careful statistical tests ensure that the results are robust and controlled for Type I error - even when based on a small sample size. Lastly, employing an eight-channel head coil constitutes a limiting factor from a technical perspective. In fact, previous studies have demonstrated the advantages of 12 - and 32 channel head coils over an eight-channel coil including improved signal-to-noise ratio, enhanced resolution, and shorted scanning times [31; 64].

\subsection{Conclusion}

Cortical reorganization in sensory and motor systems after SCI was observed as a shift in peak activation topography during sensory stimulation (i.e., brushing and heat) and active wrist extension. In agreement with a recent study in individuals with phantom limb pain [40], shifts in the primary motor cortex topography were negatively correlated 
with pain intensity, supporting an emerging theory that NP preserves cortical organization after deafferentation.

\section{Acknowledgement}

The study was supported by the Swiss National Science Foundation (SNF) and the Clinical Research Priority Program "Neurorehab" of the University of Zurich, Switzerland. John Kramer was supported by postdoctoral funding from the International Foundation for Paraplegia - Zurich, a Michael Smith Foundation for Health Research and Rick Hansen Scholar Award, and a North American Spine Society Clinical Travel Fellowship. We would like to thank all of the individuals participating in our study, and Jenny Haefeli and Alexandra Schaettin for their support in collecting data. The authors report no conflict of interests in this work.

\section{Authors Contribution}

Catherine Jutzeler contributed substantially to the conception and design of the study, the data acquisition, analysis, and interpretation. Furthermore, she drafted the research article. Eveline Huber contributed substantially to the data acquisition and participated in revising the research article. Patrick Freund contributed substantially to the conception and design of the study, the data analysis, and interpretation. He was involved in revising the research article. Armin Curt made substantial contributions to conception and design and participated in revising the research article critically for important intellectual content. John Kramer contributed substantially to the conception and design of the study, data analysis and interpretation, as well as drafting the research article. 


\section{References}

[1] Andersson JL, Hutton C, Ashburner J, Turner R, Friston K. Modeling geometric deformations in EPI time series. Neuroimage;13:903-919 2001.

[2] Becerra LR, Breiter HC, Stojanovic M, Fishman S, Edwards A, Comite AR, Gonzalez RG, Borsook D. Human brain activation under controlled thermal stimulation and habituation to noxious heat: an fMRI study. Magn Reson Med;41:1044-1057 1999.

[3] Blume KR, Dietrich C, Huonker R, Gotz T, Sens E, Friedel R, Hofmann GO, Miltner WH, Weiss T. Cortical reorganization after macroreplantation at the upper extremity: a magnetoencephalographic study. Brain;137:757-769 2014.

[4] Burns S, Biering-Sorensen F, Donovan W, Graves DE, Jha A, Johansen M, Jones L, Krassioukov A, Kirshblum S, Mulcahey MJ, Read MS, Waring W. International standards for neurological classification of spinal cord injury, revised 2011. Top Spinal Cord Inj Rehabil;18:85-99 2012.

[5] Callaghan MF, Freund P, Draganski B, Anderson E, Cappelletti M, Chowdhury R, Diedrichsen J, Fitzgerald TH, Smittenaar P, Helms G, Lutti A, Weiskopf N. Widespread age-related differences in the human brain microstructure revealed by quantitative magnetic resonance imaging. Neurobiol Aging;35:1862-1872 2014.

[6] Casey KL, Minoshima S, Berger KL, Koeppe RA, Morrow TJ, Frey KA. Positron emission tomographic analysis of cerebral structures activated specifically by repetitive noxious heat stimuli. I Neurophysiol;71:802-807 1994.

[7] Casey KL, Minoshima S, Morrow TJ, Koeppe RA. Comparison of human cerebral activation pattern during cutaneous warmth, heat pain, and deep cold pain. J Neurophysiol;76:571-581 1996.

[8] Chen JI, Ha B, Bushnell MC, Pike B, Duncan GH. Differentiating noxious- and innocuous-related activation of human somatosensory cortices using temporal analysis of fMRI. J Neurophysiol;88:464-474 2002.

[9] Costigan M, Scholz J, Woolf CJ. Neuropathic pain: a maladaptive response of the nervous system to damage. Annu Rev Neurosci;32:1-32 2009.

[10] Curt A, Alkadhi H, Crelier GR, Boendermaker SH, Hepp-Reymond MC, Kollias SS. Changes of nonaffected upper limb cortical representation in paraplegic patients as assessed by fMRI. Brain;125:2567-2578 2002.

[11] Curt A, Van Hedel HJ, Klaus D, Dietz V. Recovery from a spinal cord injury: significance of compensation, neural plasticity, and repair. J Neurotrauma;25:677-685 2008.

[12] Debaere F, Swinnen SP, Beatse E, Sunaert S, Van Hecke P, Duysens J. Brain areas involved in interlimb coordination: a distributed network. Neuroimage;14:947-958 2001.

[13] Diers M, Christmann C, Koeppe C, Ruf M, Flor H. Mirrored, imagined and executed movements differentially activate sensorimotor cortex in amputees with and without phantom limb pain. Pain;149:296-304 2010.

[14] Diwadkar VA, Murphy ER, Freedman RR. Temporal sequencing of brain activations during naturally occurring thermoregulatory events. Cereb Cortex;24:3006-3013 2014.

[15] Flor H, Elbert T, Knecht S, Wienbruch C, Pantev C, Birbaumer N, Larbig W, Taub E. Phantom-limb pain as a perceptual correlate of cortical reorganization following arm amputation. Nature;375:482-484 1995.

[16] Foell J, Bekrater-Bodmann R, Diers M, Flor H. Mirror therapy for phantom limb pain: brain changes and the role of body representation. Eur J Pain;18:729-739 2014.

[17] Freund P, Curt A, Friston K, Thompson A. Tracking Changes following Spinal Cord Injury: Insights from Neuroimaging. Neuroscientist 2012.

[18] Freund P, Rothwell J, Craggs M, Thompson AJ, Bestmann S. Corticomotor representation to a human forearm muscle changes following cervical spinal cord injury. Eur J Neurosci;34:1839-1846 2011. 
[19] Friston KJ, Holmes AP, Poline JB, Grasby PJ, Williams SC, Frackowiak RS, Turner R. Analysis of fMRI time-series revisited. Neuroimage;2:45-53 1995.

[20] Ghosh A, Haiss F, Sydekum E, Schneider R, Gullo M, Wyss MT, Mueggler T, Baltes C, Rudin M, Weber $B$, Schwab ME. Rewiring of hindlimb corticospinal neurons after spinal cord injury. Nat Neurosci;13:97-104 2010.

[21] Ghosh A, Sydekum E, Haiss F, Peduzzi S, Zorner B, Schneider R, Baltes C, Rudin M, Weber B, Schwab $M E$. Functional and anatomical reorganization of the sensory-motor cortex after incomplete spinal cord injury in adult rats. J Neurosci;29:12210-12219 2009.

[22] Giraux P, Sirigu A, Schneider F, Dubernard JM. Cortical reorganization in motor cortex after graft of both hands. Nat Neurosci;4:691-692 2001.

[23] Grusser SM, Muhlnickel W, Schaefer M, Villringer K, Christmann C, Koeppe C, Flor H. Remote activation of referred phantom sensation and cortical reorganization in human upper extremity amputees. Exp Brain Res;154:97-102 2004.

[24] Gustin SM, Wrigley PJ, Siddall PJ, Henderson LA. Brain anatomy changes associated with persistent neuropathic pain following spinal cord injury. Cereb Cortex;20:1409-1419 2010.

[25] Hirayama A, Saitoh Y, Kishima H, Shimokawa T, Oshino S, Hirata M, Kato A, Yoshimine T. Reduction of intractable deafferentation pain by navigation-guided repetitive transcranial magnetic stimulation of the primary motor cortex. Pain;122:22-27 2006.

[26] Johnstone T, Ores Walsh KS, Greischar LL, Alexander AL, Fox AS, Davidson RJ, Oakes TR. Motion correction and the use of motion covariates in multiple-subject fMRI analysis. Hum Brain Mapp;27:779-788 2006.

[27] Jurkiewicz MT, Mikulis DJ, Mcllroy WE, Fehlings MG, Verrier MC. Sensorimotor cortical plasticity during recovery following spinal cord injury: a longitudinal fMRI study. Neurorehabil Neural Repair;21:527-538 2007.

[28] Kaas JH, Qi HX, Burish MJ, Gharbawie OA, Onifer SM, Massey JM. Cortical and subcortical plasticity in the brains of humans, primates, and rats after damage to sensory afferents in the dorsal columns of the spinal cord. Exp Neurol;209:407-416 2008.

[29] Kanda M, Mima T, Oga T, Matsuhashi M, Toma K, Hara H, Satow T, Nagamine T, Rothwell JC, Shibasaki H. Transcranial magnetic stimulation (TMS) of the sensorimotor cortex and medial frontal cortex modifies human pain perception. Clin Neurophysiol;114:860-866 2003.

[30] Kang Y, Williams LE, Clark MS, Gray JR, Bargh JA. Physical temperature effects on trust behavior: the role of insula. Soc Cogn Affect Neurosci;6:507-515 2011.

[31] Kaza E, Klose U, Lotze M. Comparison of a 32-channel with a 12-channel head coil: are there relevant improvements for functional imaging? J Magn Reson Imaging;34:173-183 2011.

[32] Lacourse MG, Orr EL, Cramer SC, Cohen MJ. Brain activation during execution and motor imagery of novel and skilled sequential hand movements. Neuroimage;27:505-519 2005.

[33] Lancaster JL, Woldorff MG, Parsons LM, Liotti M, Freitas CS, Rainey L, Kochunov PV, Nickerson D, Mikiten SA, Fox PT. Automated Talairach atlas labels for functional brain mapping. Hum Brain Mapp;10:120-131 2000.

[34] Lefaucheur JP, Drouot $X$, Keravel $Y$, Nguyen JP. Pain relief induced by repetitive transcranial magnetic stimulation of precentral cortex. Neuroreport;12:2963-2965 2001.

[35] Lotze M, Flor H, Grodd W, Larbig W, Birbaumer N. Phantom movements and pain. An fMRI study in upper limb amputees. Brain;124:2268-2277 2001.

[36] Lotze M, Grodd W, Birbaumer N, Erb M, Huse E, Flor H. Does use of a myoelectric prosthesis prevent cortical reorganization and phantom limb pain? Nat Neurosci;2:501-502 1999.

[37] Lotze M, Montoya P, Erb M, Hulsmann E, Flor H, Klose U, Birbaumer N, Grodd W. Activation of cortical and cerebellar motor areas during executed and imagined hand movements: an FMRI study. J Cogn Neurosci;11:491-501 1999. 
[38] Loubinoux I, Carel C, Pariente J, Dechaumont S, Albucher JF, Marque P, Manelfe C, Chollet F. Correlation between cerebral reorganization and motor recovery after subcortical infarcts. Neuroimage;20:2166-2180 2003.

[39] Maclver K, Lloyd DM, Kelly S, Roberts N, Nurmikko T. Phantom limb pain, cortical reorganization and the therapeutic effect of mental imagery. Brain;131:2181-2191 2008.

[40] Makin TR, Scholz J, Filippini N, Henderson Slater D, Tracey I, Johansen-Berg H. Phantom pain is associated with preserved structure and function in the former hand area. Nat Commun;4:1570 2013.

[41] Maldjian JA, Laurienti PJ, Kraft RA, Burdette JH. An automated method for neuroanatomic and cytoarchitectonic atlas-based interrogation of fMRI data sets. Neuroimage;19:1233-1239 2003.

[42] Marino RJ, Barros T, Biering-Sorensen F, Burns SP, Donovan WH, Graves DE, Haak M, Hudson LM, Priebe MM. International standards for neurological classification of spinal cord injury. J Spinal Cord Med;26 Suppl 1:S50-56 2003.

[43] Marino RJ, Jones L, Kirshblum S, Tal J, Dasgupta A. Reliability and repeatability of the motor and sensory examination of the international standards for neurological classification of spinal cord injury. J Spinal Cord Med;31:166-170 2008.

[44] Mole TB, Maclver K, Sluming V, Ridgway GR, Nurmikko TJ. Specific brain morphometric changes in spinal cord injury with and without neuropathic pain. Neuroimage Clin;5:28-35 2014.

[45] Moulton EA, Keaser ML, Gullapalli RP, Greenspan JD. Regional intensive and temporal patterns of functional MRI activation distinguishing noxious and innocuous contact heat. J Neurophysiol;93:2183-2193 2005.

[46] Oldfield RC. The assessment and analysis of handedness: the Edinburgh inventory. Neuropsychologia;9:97-113 1971.

[47] Pagano RL, Fonoff ET, Dale CS, Ballester G, Teixeira MJ, Britto LR. Motor cortex stimulation inhibits thalamic sensory neurons and enhances activity of PAG neurons: possible pathways for antinociception. Pain;153:2359-2369 2012.

[48] Passe TJ, Rajagopalan P, Tupler LA, Byrum CE, MacFall JR, Krishnan KR. Age and sex effects on brain morphology. Prog Neuropsychopharmacol Biol Psychiatry;21:1231-1237 1997.

[49] Peyron R, Frot M, Schneider F, Garcia-Larrea L, Mertens P, Barral FG, Sindou M, Laurent B, Mauguiere $\mathrm{F}$. Role of operculoinsular cortices in human pain processing: converging evidence from PET, fMRI, dipole modeling, and intracerebral recordings of evoked potentials. Neuroimage;17:1336-1346 2002.

[50] Peyron R, Laurent B, Garcia-Larrea L. Functional imaging of brain responses to pain. A review and meta-analysis (2000). Neurophysiol Clin;30:263-288 2000.

[51] Peyron R, Schneider F, Faillenot I, Convers P, Barral FG, Garcia-Larrea L, Laurent B. An fMRI study of cortical representation of mechanical allodynia in patients with neuropathic pain. Neurology;63:1838-1846 2004.

[52] Poldrack RA. Region of interest analysis for fMRI. Soc Cogn Affect Neurosci;2:67-70 2007.

[53] Preissler S, Feiler J, Dietrich C, Hofmann GO, Miltner WH, Weiss T. Gray matter changes following limb amputation with high and low intensities of phantom limb pain. Cereb Cortex;23:1038-1048 2013.

[54] Schmidt CF, Degonda N, Luechinger R, Henke K, Boesiger P. Sensitivity-encoded (SENSE) echo planar fMRI at 3T in the medial temporal lobe. Neuroimage;25:625-641 2005.

[55] Schweinhardt P, Glynn C, Brooks J, McQuay H, Jack T, Chessell I, Bountra C, Tracey I. An fMRI study of cerebral processing of brush-evoked allodynia in neuropathic pain patients. Neuroimage;32:256-265 2006.

[56] Siddall PJ, Loeser JD. Pain following spinal cord injury. Spinal Cord;39:63-73 2001.

[57] Siddall PJ, McClelland JM, Rutkowski SB, Cousins MJ. A longitudinal study of the prevalence and characteristics of pain in the first 5 years following spinal cord injury. Pain;103:249-257 2003.

Page $\mathbf{2 7}$ of $\mathbf{2 8}$ 
[58] Simoes EL, Bramati I, Rodrigues E, Franzoi A, Moll J, Lent R, Tovar-Moll F. Functional expansion of sensorimotor representation and structural reorganization of callosal connections in lower limb amputees. J Neurosci;32:3211-3220 2012.

[59] Tamura Y, Okabe S, Ohnishi T, D NS, Arai N, Mochio S, Inoue K, Ugawa Y. Effects of 1-Hz repetitive transcranial magnetic stimulation on acute pain induced by capsaicin. Pain;107:107-115 2004.

[60] Tombari D, Loubinoux I, Pariente J, Gerdelat A, Albucher JF, Tardy J, Cassol E, Chollet F. A longitudinal fMRI study: in recovering and then in clinically stable sub-cortical stroke patients. Neuroimage;23:827-839 2004.

[61] Topper R, Foltys H, Meister IG, Sparing R, Boroojerdi B. Repetitive transcranial magnetic stimulation of the parietal cortex transiently ameliorates phantom limb pain-like syndrome. Clin Neurophysiol;114:1521-1530 2003.

[62] Turner JA, Lee JS, Schandler SL, Cohen MJ. An fMRI investigation of hand representation in paraplegic humans. Neurorehabil Neural Repair;17:37-47 2003.

[63] Ward NS, Brown MM, Thompson AJ, Frackowiak RS. Longitudinal changes in cerebral response to proprioceptive input in individual patients after stroke: an FMRI study. Neurorehabil Neural Repair;20:398-405 2006.

[64] Wiggins GC, Triantafyllou C, Potthast A, Reykowski A, Nittka M, Wald LL. 32-channel 3 Tesla receiveonly phased-array head coil with soccer-ball element geometry. Magn Reson Med;56:216-223 2006.

[65] Wrigley PJ, Press SR, Gustin SM, Macefield VG, Gandevia SC, Cousins MJ, Middleton JW, Henderson LA, Siddall PJ. Neuropathic pain and primary somatosensory cortex reorganization following spinal cord injury. Pain;141:52-59 2009.

[66] Yoon EJ, Kim YK, Shin HI, Lee Y, Kim SE. Cortical and white matter alterations in patients with neuropathic pain after spinal cord injury. Brain Res;1540:64-73 2013. 